\title{
Study on Orienteering in the View of Ecological Sports
}

\author{
Qing LAN \\ Yichun University, Yichun, Jiangxi, China
}

\begin{abstract}
The article proposed the definition of orienteering from the perspective of ecological sports, performed innovative teaching studies, adopting document literature and interviewing method as the basic research methods, based on the current teaching status of orienteering, from aspects such as the cultural environment of ecological sports resources, green technology, orienteering teaching as well as the socialization of orienteering etc.. It has provided feasibility reference for the education and teaching of orienteering.
\end{abstract}

KEYWORD: Ecological sports; Orienteering; Innovative teaching

\section{FOREWORD}

"Reformation will make things unobstructed so as to achieve purpose" makes profound philosophy sense, but also has broad implied meanings. For thousands of years of Chinese education development, it has experienced the spiral promotion, following establishment of education teaching mode and system, stabilization, reformation, and reestablishing. Professor R.G. Havclock, an international famous expert on education reform theory has ever defined "educational reform" as below: "Education reform refers to any significant change on present education situation". Orienteering, since from being introduced into China mainland in 1983, played an important role on promoting students' health on school physical education as being characterized of "a kind of sunny sports movement done in forests, rivers, and vegetation". However, when deepening into the current situation of education teaching, it is basically adhering to the traditional sports skill teaching methods, which have certain limitations and traditional characteristics.

Therefore, undoubtedly, it is a great development of the traditional teaching method to change the teaching idea, perform innovative teaching of orienteering with a new angle, transform from stage sports to lifelong sports, from focusing on sports skill to human health, from discipline theory to humanism, and transform to ecological sports teaching based on "people" to form a balance chain of ecological sports.

\section{ORIENTEERING FROM THE PERSPECTIVE OF ECOLOGICAL SPORTS}

Ecological sports is originated from the simple idea of the "theory that man is an integral part of nature" and it is formed with the contradictions between human and nature, human and the society, human and human, sports and the environment during the contemporary sports activities. Ecological sports embodies the harmony and unity between nature, human and sports. Orienteering is a movement to find the point targets marked on a map with the help of maps and a compass, in accordance with the sequences specified on the map in the shortest possible time successively. The writer believes that from the aspect of ecological sports, orienteering can be explained by sky, earth and human. "Sky" refers to the nature environment, "earth" refers to maps and "human" refers to people taking part in the orienteering, people with social attribute. The perfect overall three dimensional states of sky, earth and human is the highest state of orienteering.

\section{ORIENTEERING OF THE INNOVATIVE TEACHING UNDER THE PERSPECTIVE OF ECOLOGICAL SPORTS}

What the ecological sports embody is the relationship or contact activities formed by the mutual coordination, coexistence and co-prosperity and common development of the human being, sports and the environment, presenting as the overall 
dynamic harmony between human being and nature, human and the society, human being itself. The ecological environment of orienteering includes two dimensions, natural environment and social cultural environment. The ecological sports view shows as the original ecological of the sports site, the concurrency between technology and environmental protection of orienteering development; humanistic perspective of orienteering; social harmony of orienteering development.

\subsection{Original ecological and technological teaching of orienteering under the perspective of ecological sports}

The higher education in China has entered the phase of mass education from the beginning of the 21st century. School education resources demands expand consequently. Large-scale campus constructions occurred, represented by higher education parks, which caused deliberate destructions of the ecological resources. At the same time, the development of high-tech promoted the advancing of orienteering, but lost the ecological balance of green environmental protection.

A new concept is given to orienteering teaching by ecological sports: concurrency between technology and environmental protection. Orienteering provides a new connotation to "environmental protection": original ecology of teaching resources, rationalization of usability; environmental protection property of high-tech teaching technique and teaching aids.

\subsubsection{Ecological resources of orienteering teaching under the perspective of ecological sports}

Orienteering is deeply welcomed by students as hugging the nature, integrating with the nature, returning of the wild. Therefore, the limitation of orienteering teaching site to the campus will cause students' cognitive fatigue and visual fatigue towards the causes. Combining with the characteristics and growth regulations of students in different developmental stages, breakthrough the limitation of traditional teaching site, stimulate the students' brain centers unceasingly by the new teaching environment. The construction of Chinese education presents a construction planning characterized of higher education park. Scientific and reasonable resource sharing is required by social resources saving and ecological environment balance development, as well as a manifestation of the "environment protection" of orienteering teaching. Orienteering is to extend the students' teaching space by strengthening intercollegiate exchanges, teaching places, instructional maps sharing; the ancillary facilities around the school such as leisure parks, can mobilize students' excitability, and freshness on learning, and add a beautiful scene for the park, becoming an entertainment for the travelers. It will lay the foundation for the socialization of orienteering, and cultivating the students' lifelong sports concept.

\subsubsection{Technology and environmental protection na- ture of orienteering teaching under the pers- pective of ecological sports}

Ecological sports is dynamic and sustainable. Sports science and technology shall promote the development of sports, and highlight its value in the green environmental protection as well which is advantageous to the prospective development of ecological sports. Advanced education technology and high-tech teaching aids for orienteering teaching shall be based on the "environment protection" concept, which is the command bar to guiding the technology moving forward.

First of all, the original teaching techniques and teaching aids of orienteering are relatively simple. We can complete the teaching with hand-painted maps, point target flags and manual clock card. Most of the hand-painted maps will cause waste of human resources and manual clock card has certain disadvantages either; not only the teachers can't accurately judging students clocking sequence, but also the paper cards used by the students cannot be recycled which is a waste of paper resources. Advanced electronic clock system will be used which is green and environmental protection. Secondly, we need to have the courage to try new things and identify genuine knowledge through comparison. Drawing hand-painted maps is the preparations before class which wastes time and labor. Before the completion of the professional orientation map, we may try to use satellite maps for targeted teaching during the buffer period. We can try to use satellite maps at the earlier stage since it can search simply and display in details. Sum up the experiences during the trial.

\subsection{Humanistic teaching of orienteering under the perspective of ecological sports}

Both from the education view "people oriented" of the education in China to the core concept of physical education "health first", the value orientation of humanistic education are reflected. Expanding the humanistic vision of orienteering and transforming the physiological sport concept to humanistic sports health perspectives can deeply indicate the respects to teachers' leading role and students' main body status and build a orienteering teaching humanities environment of harmony and full of vitality and cohesion. 


\subsubsection{Teaching method of orienteering embodies humanistic}

Orienteering teaching combines with school's history cultural environment closely. Orienteering is a movement to find the point targets marked on a map with the help of maps and a compass. The point target on the map is a single circle of $0.7 \mathrm{~cm}$ in diameter. The sequence of marking is in Arabic numerals. Such teaching method is standard, while lacks of humanism. Taking the names of historical figures of the school, important historical events, historical courses and school cultural constructions as point targets can promote students' learning in school humanities knowledge, strengthen students' awareness and enhance the students' sense of honor about the school.

Orienteering teaching combines with students' major closely. The learning ability of orienteering can be summarized as running ability; the ability to read maps and analyze maps; the ability to compare the map and the actual site (namely the 3D reading ability of map). Different students have great specialty differences, therefore, in the process of teaching, students will be divided into different classes according to their majors and individual differences. Give full play to students' individual potential, and embody the humanistic concerns of education. On the basis of junior, medium and senior multi-level teaching, perform parallel class grouping according to their majors and individual differences once more, which add features to the humanistic teaching of orienteering, presenting varying with each individual and teaching students in accordance of their aptitudes.

\subsubsection{Assessment of orienteering embodies huma- nistic care}

Olympic Games raised the banner of "swifter, higher, and stronger" to promote the Olympic. It is the high competitive spirit composed by countless sporting heroes on the playground; the five interlocking rings on Olympic Games flag not only symbolize the mutual affinity between five continents, but also embody the humanistic spirit of the activity. Competition is a form of exercise. The humanistic spirit is the soul of condensate field of the activity. Permeating the form and soul of Olympic games into the assessment of orienteering is a state with the most nobility, sincerity and beauty. Athletes taking stimulant during the competition deprives people's right to health; the malicious biased of referee is unfair to the competition; acrimonies to competitors and damaging to the competition rules cause disrespect to the people and rules. Directional assessment adopts the form of a game. The game players shall adhere to fairness and good faith principle during the competition: not running for others, not survey site ahead of schedule, not by means of transport. Respect for the competitor, and follow the rules of the competition: keep friendly and good relationship with competitors. Do not disturb the competitor deliberately. Do not accept game information from others and do not provide them to others. Strictly follow the competition rules of the game. Orienteering is mainly to cultivate athletes the ability to independent analyze and solve problems, to have rapid response and encourage of innovation. Playing the spirit of perseverance, courageous and innovation during the assessment competition is the deep explanatory of humanity. Students' connotation and two-way denotation cultural is the teaching appraisal target of orienteering.

\subsection{Socialized teaching of orienteering under the perspective of ecological sports}

As a concept of the sport sociology, sports socialization mainly involves two aspects: "the first one is entering sports socialization, which means that what kind of social structure and social factors people depend on to participate in sports activities; the second one is that socialization through sports, which means that the individual socialization process of people by playing sports to master the value of sports, to cultivate social role, to develop physical quality, promote the formation and development of the individual. "

In modern times, "leisure sports", "sports tourism" spring up exuberantly in wide nature "land", "water", "air" etc., the outdoor sports for the purpose of health, advocating natural, persuading of harmony, and realizing the entire development of individual and life enrichment can further motivate people's love to the nature and real life. School sports is the origin of mass sports and competitive sports. Thus it is a necessary factor for sports socialization and harmonious development of social sports to do well in the connection between school sports and society sports, and cultivate the students and the mass of lifetime sports concept.

Cultivating the students' lifelong sports concept is the basis of realizing sports socialization. Change the teaching thought of focusing on competition and ignoring the process during the teaching process at orienteering teaching. Put emphasis on the gradual permeation of sports knowledge, exercise consciousness and behavior habits during the teaching process. Carry out socialized teaching by putting point of strength on appreciation entertainment of orienteering at the same time. Carry out orienteering teaching or competition outside the campus. The game scene will be intense with high ornamental value and entertainment. It is a transforming step of orienteering socialization that the public gets awareness of orienteering, and is 
interested in participating in orienteering experience through entertainment.

\section{CONCLUSION}

Realize orienteering teaching resources sharing in colleges and universities through cooperation between schools. Expand students' learning space. Realize the teaching resources ecology, in order to change the current status of visual fatigue, cognitive fatigue to stimulate brain learning centers and enhance learning effects of students.

Overall consideration of the concept of green environmental protection and sustainable development point of view. Have the courage to try and identify the teaching application of high-tech technologies and products. Do no abuse nor reject.

Expand the orienteering humanistic vision. To strengthen humanistic care to students from aspects such as teaching method of orienteering, teaching assessment etc.. To build an orienteering teaching humanities environment of harmony and full of vitality and cohesion.
Fading the competitiveness of teaching skills of orienteering. Prominent developing of students' consciousness of lifetime sports concept and exercise behavior is the link between school sports and social sports. Meanwhile put emphasis on the social impact of orienteering, improve the social functions of orienteering, and promote the socialization of the project.

\section{REFERENCES}

[1] Liu, L.L. 2010. Research on the construction of ecological sports development in the background of Harmonious Society. Sports World Scholarly (3): 68-69.

[2] Meng, Y. 2001. Stepping to Urban Cultural Ecology of the "Theory that Man is an Integral Part of Nature" Journal of South China University of Technology (3): 3134.

[3] Lei, Z. 2008. Prospect of sports socialization of China. Sports Culture Guide 25(2): 22-24.

[4] Yan, X.F. 2002. Orientation and Construction of Ethics of Social Sportsmanship. Journal of Beijing Sport University 25(1): 29-32.

[5] You, H.Y. 2008. Sport ecology. Sichuan: China. 